\title{
Difficult Diseases: Tuberculosis and Other Infections
}

\section{INTRODUCTION: ELSIE AND MOHAMMED}

A Muslim couple, Elsie and Mohammed, arrived at Victoria Station, London, in January 1915. They were refugees fleeing war-torn Belgium. Born in 1883, Elsie was a dressmaker and "artistic worker". Her mental troubles began following the birth of her daughter:

She was very depressed, weeping and covering her face with her hands. She kept getting out of bed and attempting to escape. She refuses her food at times. She has been in this depressed condition for some time and shows no improvement.

After two years in Hanwell she moved to Colney Hatch, the London County Council (LCC) asylum which admitted many patients born abroad and for whom English was not their mother tongue. At Colney Hatch, she could be alongside other Belgian refugees, which might provide a more favourable social and therapeutic environment for her than Hanwell. Elsie suffered an episode of dysentery in October 1917. A few weeks later physical examination revealed some weight loss and dullness in her left lung. She died of tuberculosis in April 1918. ${ }^{1}$ The post-mortem noted "bed sores" (today, pressure sores or ulcers), which, according to psychiatrist Charles Mercier, were "a discredit to an attendant, and ought never be allowed in an asylum patient", a statement with which the asylums' Board of Control ("the Board") concurred. ${ }^{2}$ Elsie's

(C) The Author(s) 2021

C. Hilton, Civilian Lunatic Asylums During the First World War, Mental Health in Historical Perspective, https://doi.org/10.1007/978-3-030-54871-1_7 
weight loss could have been due to dysentery or tuberculosis or to her mental state. Tuberculosis was alarmingly frequent in asylums, and dysentery was "deplorably common", 3 although almost non-existent in the general population, to the extent that one asylum medical officer argued that fear of catching it reduced asylum admissions. ${ }^{4}$

Elsie's family arranged for a "Muslim priest" to officiate at her funeral. ${ }^{5}$ A few weeks later, Mohammed wrote to the authorities:

Kindly return to above address all belongings from late Elsie $\mathrm{M}-\mathrm{s}$. Should the Medical Superintendent, the Committee, etc., etc., think the belongings are not fit for discharge, they may do what they have done with Elsie $\mathrm{M}-\mathrm{s}$.

Mohammed's message reverberates with distress. The asylum sent him her belongings, a wedding ring and dress ring, by registered post. They forwarded her "plate of artificial teeth" to the Paddington Guardians, their rightful owners. Her clothes and other day-to-day items were asylum property. ${ }^{6}$

Deaths in asylums, particularly from infectious diseases, escalated during the war. The increase may have been related to the many wartime changes we have seen so far, including: vacating asylums to create war hospitals which resulted in overcrowding of those remaining; many inexperienced staff and low staff morale; and inadequate food, fuel, clothing, bathing routines and other basic amenities. In this chapter we shall explore aspects of medical and scientific knowledge concerning infectious diseases and how that knowledge was applied in the asylums. The various themes all relate to Elsie's story: death rates; post-mortems; tuberculosis; and other infectious diseases.

\section{Death Rates and Post-mortems}

In 1914, based on diagnosis during life plus post-mortem evidence, tuberculosis, general paralysis of the insane (GPI, brain syphilis), and the vague category of "senility" accounted for over one third of total asylum deaths in England and Wales. ${ }^{7}$ GPI was discussed in Chapter 3, and aspects of the other two categories are discussed below. The overall annual asylum death rate of under ten per cent rose to 12 per cent in 1915-1916, leaped to over 17 per cent in 1917 (resulting in the LCC discussing paying overtime to asylum mortuary attendants ${ }^{8}$ ) and peaked in 1918 at 20 per cent 
(Table 7.1). ${ }^{9}$ There was little alarm, because the causes of death were the same as pre-war and the rise did not point to staff directly failing in their duty of care according to the Lunacy Act, resulting in suicide or injury. The total asylum population in England numbered around 100,000 and the national population over 32 million, but during the war half the total national increase in tuberculosis deaths occurred in the asylums. ${ }^{10}$ Regarding the incidence and death rates of other acute infectious diseases, asylums compared unfavourably with the general population, including in London, where they remained comparatively low throughout the war. ${ }^{11}$

Table 7.1 Deaths in asylums: mortality per 1000 resident patients and total deaths

\begin{tabular}{|c|c|c|c|c|c|c|c|c|}
\hline & 1913 & 1914 & 1915 & 1916 & 1917 & 1918 & 1919 & 1920 \\
\hline \multicolumn{9}{|c|}{ Mortality per 1000 resident patients } \\
\hline $\begin{array}{l}\text { General } \\
\text { Paralysis }\end{array}$ & & 15.7 & 16.5 & & & 17.5 & & 13.6 \\
\hline Dysentery & 2.2 & 2.5 & 4.0 & 5.0 & 10.0 & 9.0 & & 2.6 \\
\hline Typhoid & 0.3 & & 0.6 & 0.5 & 1.2 & 1.1 & & 0.4 \\
\hline \multirow[t]{2}{*}{ Tuberculosis } & 17.0 & 12.5 & 19.0 & 23.0 & 37.0 & 51.8 & & 15.8 \\
\hline & & $\begin{array}{l}\text { Tuberc } \\
\text { residen }\end{array}$ & $\begin{array}{l}\text { losis mort } \\
\text { s, not age }\end{array}$ & $\begin{array}{l}\text { ality per } \\
\text { adjusted }\end{array}$ & $1000 \mathrm{com}$ & munity & & \\
\hline \multirow[t]{2}{*}{ Tuberculosis } & 1.35 & & 1.51 & 1.53 & 1.62 & 1.69 & & 1.13 \\
\hline & \multicolumn{8}{|c|}{ Total asylum deaths } \\
\hline $\begin{array}{l}\text { a. Total } \\
\text { asylum } \\
\text { deaths }\end{array}$ & 10,075 & 10,594 & 12,710 & 12,888 & 17,130 & 18,330 & 11,217 & 7945 \\
\hline $\begin{array}{l}\text { b. Total } \\
\text { asylum } \\
\text { patients }\end{array}$ & 104,868 & 106,451 & 105,858 & 103,574 & 98,621 & 90,459 & 86,950 & 90,950 \\
\hline $\begin{array}{l}\text { Deaths } \\
(\mathrm{a} / \mathrm{b}) \\
\text { per cent }\end{array}$ & 9.6 & 9.9 & 12.0 & 12.4 & 17.4 & 20.3 & 12.9 & 8.7 \\
\hline
\end{tabular}

Sources BoC, "Increased Annual Death Rate in Asylums," 15 January 1919, 532 MH 51/239 TNA; Second Annual Report of the Board of Control, for the Year 1915 (London: HMSO, 1917), 12-13; BoC AR 1918, Appendix A, 27; Seventh Annual Report of the Board of Control, for the Year 1920 (London: HMSO, 1921), 26; Drolet, "World War I and Tuberculosis": 690 
Death rates provide important evidence about disease, but like other data, they are not infallible, they have limitations and require careful interpretation. They do not measure new occurrences the disease, neither how long it lasts nor how severely it incapacitates the sufferer. They are therefore somewhat crude measures of disease activity. Waltraud Ernst, in his study of death rates in asylums, noted problems of "the nature of the statistics on which they are based and the categorizations underlying them", associated with doubtful validity and reliability of the figures collected. ${ }^{12}$ Caution is also needed when comparing rates of disease and death between asylums and community because figures may not be adjusted for different age distributions. Death rates, however, were not confounded by transferring seriously physically ill asylum patients to general hospitals or sanatoria as they were treated in-house. Also, comparing two relatively small asylums, in 1914, Northumberland Asylum to the east of the Pennines had the highest annual death rate nationally (38 per cent) and Cumberland and Westmorland to the west had the lowest (nine per cent), ${ }^{13}$ suggesting that death rates were not directly related to asylum size.

A patient who died in an asylum was typically subject to a post-mortem examination. ${ }^{14}$ Post-mortems indicated to the rest of the medical world that the care of lunatics was part of medical practice and that asylum doctors sought to improve their understanding of cause and pathology of the disorders from which their patients suffered, just as their colleagues in general hospitals. However, interpretation of post-mortem examinations and the terminology used in reports could be ambiguous. ${ }^{15}$ Differences were likely to have been due to the skills and understanding of individual pathologists, as illustrated by the use of the terms derived from the word "senile". 16 "Senility" was often used synonymously with old age, when the body's organs shrink or "atrophy" in later life. Not only was there was no specified chronological age designating "old", but senility might affect only one part of the body, such as baldness, a type of "early local senility". ${ }^{17}$ At Hanwell, reports from a consecutive sample of ten post-mortems of men age over 60 concluded that the main cause of death for all of them was "senile decay", of whom three were also labelled as having "senile dementia". ${ }^{18}$ In contrast, in a similar series of ten at Colney Hatch carried out by a different pathologist, none mentioned senile decay. Only three included the term senile in any form, but each was used in a different way: senile debility, senile dementia 
and senility. ${ }^{19}$ Drawing on all twenty of these post-mortems, three of the four whose cause of death was attributed to "senile dementia" had normal weight brains, making that conclusion unlikely. Overall, when incorporated into death certificates, imprecise senility-related terms lacked scientific or clinical meaning. The label was convenient, subjective and detracted from the need to acknowledge other pathology which might have more accurately explained the death. The post-mortem of James $\mathrm{K}$ age 64 demonstrates this. The pathologist found his brain to be normal but intestines "congested and inflamed", suggesting dysentery, but the report concluded that the primary cause of death was senile decay with dysentery secondary. ${ }^{20}$ This sort of conclusion would under-estimate the number of deaths due to preventable infections.

Routine post-mortems were controversial, taking little account of their emotional significance for bereaved relatives. The Board advised seeking consent from a patient's relative at the time of admission to the asylum, to agree to a post-mortem in the event of their death. The request for consent appeared in the standard admission letter sent to the relative, alongside information on more immediate matters, such as visiting times. At the time of admission to an asylum, which portrayed itself as an institution offering hope of recovery and not as somewhere that patients were sent to die, the relative was more likely to be concerned about current problems and recovery, making them unlikely to pay attention to information about death. However, unless the relative objected in writing to the post-mortem, consent was inferred. ${ }^{21}$ With the original notification long forgotten, a post-mortem could distress relatives who were under the impression that they had not consented to it. ${ }^{22}$ Fulham Board of Guardians sharply reprimanded Hanwell asylum's "visiting” committee (VC) for neither informing a husband of his wife's death nor explicitly requesting consent at that time concerning performing a post-mortem. The VC discussed the Guardians' letter and replied that it would not change its practice. ${ }^{23}$ As with other practices, the process reflected institutional convenience rather than the wellbeing of the patient or his family. The asylum did not have to respond in such a callous way. Pamela Michael and David Hirst described how customs and rules about communication concerning deceased patients at Denbigh Asylum in Wales were influenced by local culture. ${ }^{24}$ Doing the same at Hanwell for a diverse urban population would have been more complicated, but feasible. The different approaches suggest that asylums interacted in different ways with the populations they served. The Denbigh leadership showed more 
compassion and flexibility in this matter than the Board recommended, or Hanwell VC applied.

\section{Tuberculosis}

The wartime rise of asylum tuberculosis needs to be contextualised in its pre-war course and how the authorities responded to it. For over a decade, rates of asylum tuberculosis were approximately ten times higher than in the community. ${ }^{25}$ There were two hypotheses to explain this: either insane people had an inherent predisposition to tuberculosis alongside their mental disorder in accordance with "degeneration" theories; or, asylum conditions predisposed to it. ${ }^{26}$ Dr. Francis Crookshank, in 1899 , blamed the asylums, "the fault lies with the institution harbouring the germs. It is no excuse that the person infected has "family tendencies." $27 \mathrm{He}$ attributed high rates to overcrowding, poor ventilation, lack of out-door activity, unhygienic wards and "a certain quality of diet."28 To Crookshank, environmental and dietary remedies were needed, and were morally and economically justified on the grounds that improvements would enable long-term patients to work better and acute patients to recover faster. He also recommended segregating patients known to be infectious, and weighing all patients every three months since weight loss often accompanied early stages of tuberculosis. ${ }^{29}$

Soon after Crookshank's critique, the Medico-Psychological Association (MPA) appointed a Tuberculosis Committee to investigate. It concluded that high rates of tuberculosis in public asylums called for urgent measures. ${ }^{30}$ It made recommendations, but implementation was hardly detectable. Psychiatrist William Stoddart blamed the asylum leadership, "underfeeding and overcrowding, enforced...by lay committees with excessively economical tendencies". ${ }^{31}$ Psychiatrist and researcher Frederick Mott, based on his pre-war study of tuberculosis, stressed the importance of early diagnosis with a view to ensuring the patients' "isolation and treatment" and that they expectorated into "proper receptacles". ${ }^{32} \mathrm{He}$ also specified the need, with which the Board concurred, for asylums to provide wards with verandas deep enough to shelter beds for outdoor nursing (Fig. 7.1). ${ }^{33}$ Mott reassured the LCC asylums that they were already taking adequate dietary and environmental measures to prevent tuberculosis, ${ }^{34}$ which, in view of his standing regarding science and asylums, risked encouraging complacency even if his view was accurate and appropriate for some. The Board encouraged, and reiterated 


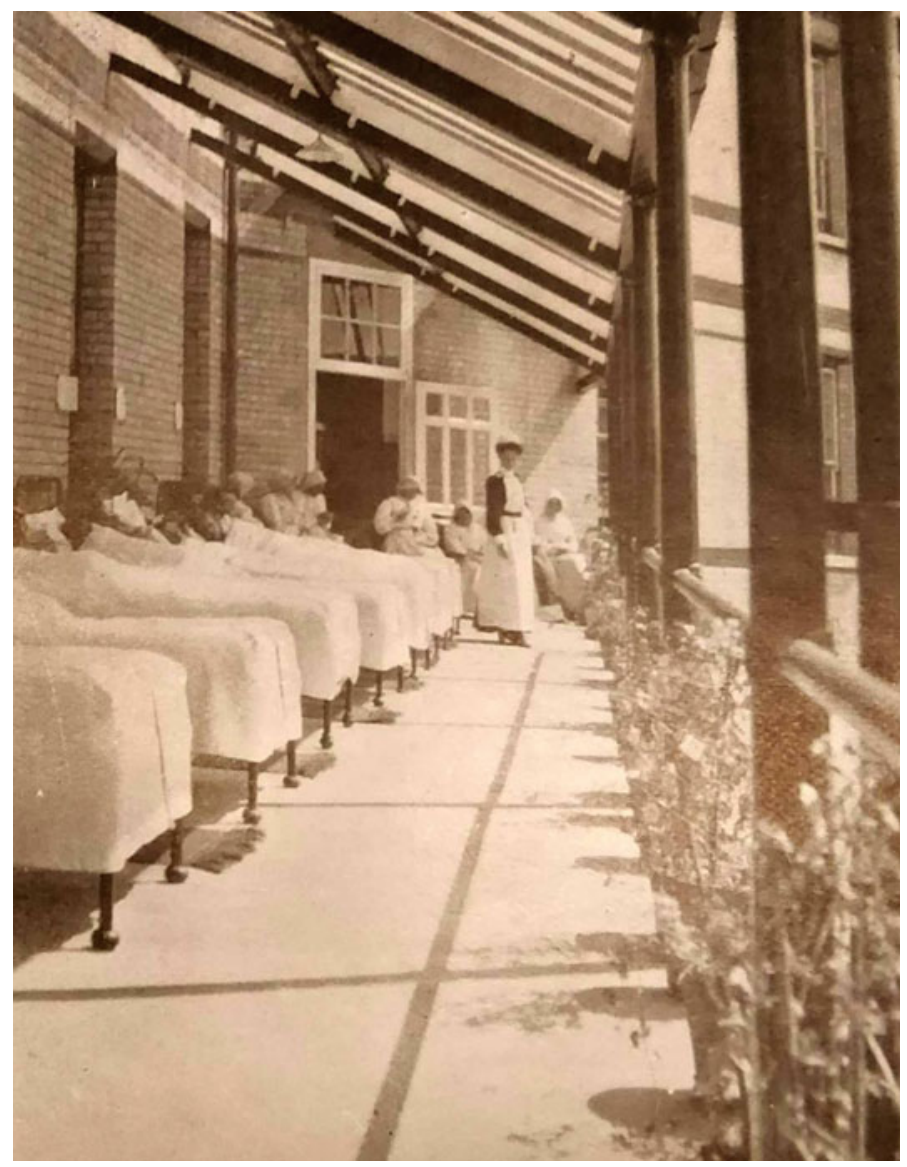

Fig. 7.1 Verandah for nursing patients with tuberculosis in the open air, at Horton Asylum. Given to Mott by the medical superintendent. Photographer unknown (Mott, "Tuberculosis in London County Asylums”: opposite, p. 116)

during the war, the need to regularly weigh patients, as Crookshank and others had advised, but implementation varied. ${ }^{35}$ Also in the war years, most experts recommended physical examination rather than X-ray screening to detect lung tuberculosis, but with medical staff shortages the standard three-monthly physical health checks for patients were abandoned, with the risk of overlooking new or emerging cases. ${ }^{36}$ 


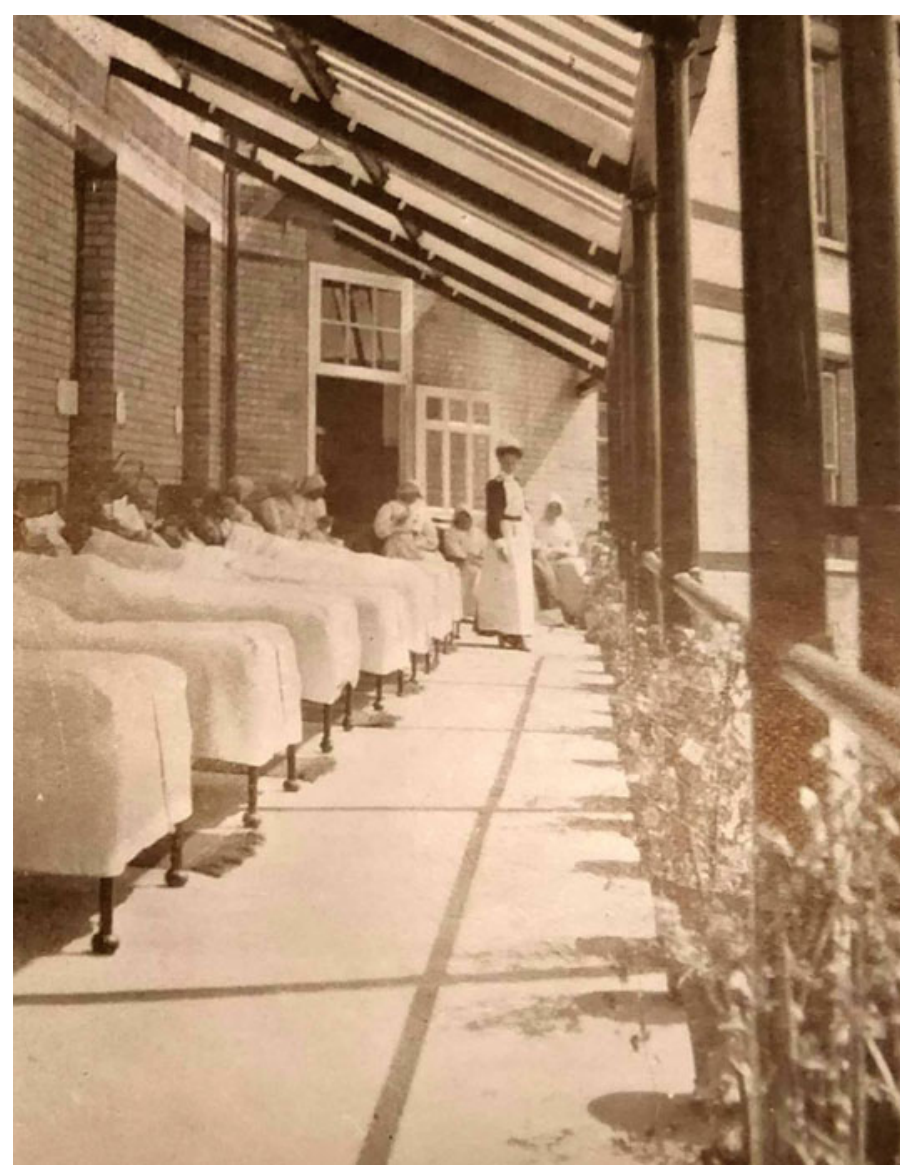

Fig. 7.1 (continued)

In the community, many adults harboured the mycobacterium causing tuberculosis, so some asylum deaths would have included patients admitted with latent, smouldering, quiescent, or inactive disease which ripened into a full-blown, rapidly fatal condition activated by wartime asylum deprivations. ${ }^{37}$ Some patients arrived in asylums suffering from tuberculosis, such as Lily R, whose story appears in Chapter 3. Others, such as Elsie M probably acquired it after admission. Numerous asylum 
practices, known to be unhygienic, risked spreading it and other infectious diseases. Practices included: treating healthy and infectious patients together in open wards; patients not washing their hands before meals or after using the lavatory; inadequate hand washing by people preparing food and working in the laundry; lack of measures to prevent inhalation of mycobacterium tuberculosis; and drying soiled underclothing in the ward to be worn again without washing. ${ }^{38}$ Some asylum laundries used washing machines and the disinfectant chlorine, which could be produced by electrolysis of brine at the asylum, ${ }^{39}$ but foul linen was handled too often, including counting items into the laundry to ensure accountability for losses. Many asylums had insufficient isolation wards, especially during the war, lacked laboratory facilities to confirm infectious diseases, and communicated poorly about patients with the disorders when transferring them between wards or asylums. ${ }^{40}$

Asylum ward staff were expected to be able to take patients' temperatures, identify physical symptoms and inform the doctor about them, and to be able to nurse patients with tuberculosis, including 24-hours in the open air. ${ }^{41}$ Temporary and untrained ward staff during the war were less likely to have these and other nursing skills, which may have been a factor in Elsie M developing not just tuberculosis, but also bed sores.

The LCC instructed asylums late in 1914 to vacate their detached villas, including some in use as isolation wards, as they were required for war purposes. Infectious patients were moved back into the main buildings. ${ }^{42}$ With inadequate isolation and an under-trained workforce, standards of infectious disease management fell. The LCC may have had patriotic intentions but it is less clear that it understood the health risks associated with the instructions it gave.

Although notification of new cases of tuberculosis to the local authority Medical Officer of Health $(\mathrm{MOH})$ became mandatory from $1912,{ }^{43}$ not all asylums and $\mathrm{MOH}$ complied. Some $\mathrm{MOH}$ allegedly discouraged the asylums from notifying them. Even where asylums sent notifications, the $\mathrm{MOH}$ did not always transfer them to the official responsible for treatment in the locality where the asylum was situated, forwarding them instead to the MOH of the area from which the patient was admitted. ${ }^{44}$ The Board received copies of death notices, but not copies of new diagnosis notifications. ${ }^{45}$ This could have affected the Board's perception of the situation, diminishing its concern and reducing the likelihood of it endeavouring to provide prophylactic measures or better treatment. Overall, nobody in authority had a comprehensive picture of tuberculosis 
in asylums, nor took responsibility to counter the rising rates. Without being informed about diagnoses, the Board was also unlikely to know that over 90 per cent of asylum tuberculosis occurred in the lungs rather than in other parts of the body, compared to 75 per cent of community tuberculosis. ${ }^{46}$ This meant that asylum tuberculosis was transmitted disproportionately by inhalation, associated with poor hygiene and lack of ventilation, rather than by it being ingested in infected milk or meat. ${ }^{47}$

Psychiatrist and historian John Crammer attempted to unravel the underlying causes of high tuberculosis incidence and mortality in his analysis of wartime deaths at the Buckinghamshire Asylum. He noted that the escalating deaths received little attention from the Board or the VC. ${ }^{48}$ Wartime understaffing of the Board meant that one, rather than two, inspectors carried out asylum inspections, often a lawyer unaccompanied by a doctor. It is questionable whether lawyers had enough medical knowledge to respond adequately on matters of disease and death, but the annual inspection box had to be ticked, and a lawyer's inspection ensured that this happened. In 1917, medical superintendents made their concerns known to the Board, attributing rising death rates to food restrictions which predisposed patients to succumb to infection. ${ }^{49}$ The Board appeared complacent, but the LCC was sufficiently alarmed to commission Mott to re-investigate tuberculosis in its asylums, although the minutes do not report his conclusions. ${ }^{50}$ The LCC commissioned its investigation over a year before the Board began its study. ${ }^{51}$

Crammer identified overcrowding and poor nutrition as important causes. Overcrowding may have contributed to spreading tuberculosis but did not relate directly to death rates which peaked at the same time in asylums with and without it. ${ }^{52}$ Concerning food, Crammer focussed on the reduction in the bread allowance, and thus the calorie intake, causing slow starvation resulting in lethargy, apathy, lowered vitality and impaired resistance to infection. He argued that Scottish asylums had a less steep rise in tuberculosis than English because the former had better food. ${ }^{53}$ However, the picture was more complicated: the rise outside the asylums in Scotland was also smaller than in England. ${ }^{54}$ Elsewhere, diet and tuberculosis mortality showed poor correlation: in Germany, for example, severe wartime malnutrition was unaccompanied by a proportional rise in tuberculosis. ${ }^{55}$ Returning to England, asylum death rates diminished post-war before the diet improved (Table 7.1$), 56$ also suggesting factors other than diet contributed to the tuberculosis death rate. 
Workhouses in England had dietary regimes similar to those in asylums but did not experience a parallel escalation of tuberculosis. Before the war, many workhouses had vacancies, ${ }^{57}$ and full employment in wartime may have emptied them further. Thus, although workhouses were requisitioned for military purposes like the asylums, those which remained as civilian facilities, did not suffer the same degree of overcrowding. Also, physical activity was strictly enforced in workhouses. This gave some protection against tuberculosis due to exercise being associated with better lung expansion. By contrast, asylums encouraged, but did not enforce, activity for people with severe chronic mental disorders such as schizophrenia and melancholia, for whom physical inertia may have increased their risk. ${ }^{58}$

Staff also risked contracting tuberculosis, but Mott could not demonstrate conclusively that they acquired it from patients. ${ }^{59}$ All new staff were examined physically when they entered the asylum service. Some may have had undetectable, quiescent disease when they joined, and others may have acquired the infection while working there. ${ }^{60}$ Staff also continued to work if the doctor decided that their disease was inactive, ${ }^{61}$ and occasionally they died from the disease while still in service. ${ }^{62}$ This raises questions of how ill and infectious a staff member might be while working with asylum patients. The LCC (General Powers) Act 1910 permitted asylum staff to receive sanatorium treatment, but this was not an option for patients. Asylum patients remained in the institution if they developed tuberculosis, but resident staff only remained there if their disease was considered unlikely to benefit from sanatorium treatment. Treatment for staff was inequitable with that for asylum patients, a situation unjustifiable on medical and public health grounds, but one to which the Lunacy Act contributed, because sanatoria were not licenced to accept certified lunatics. When a Banstead Asylum attendant, John Johnson, was too unwell to travel by rail to a sanatorium, the asylum paid $25 \mathrm{~s}(£ 1.25 \mathrm{p})$ to transfer him by car, and agreed to pay $35 \mathrm{~s}$ a week for his in-patient treatment. ${ }^{63}$ This weekly fee was over twice the amount spent on a patient in an asylum, suggesting that staff were regarded as valuable to the community compared to mentally unwell people who were frequently perceived as a long-term burden on the state.

In September 1918, Board leaders met with chief medical officer Sir Arthur Newsholme, to discuss the high death rate. Newsholme promised his department's cooperation. ${ }^{64}$ The Board delegated three of its medical 
members, Sidney Coupland, Arthur Rotherham and Robert Branthwaite, to investigate asylums with the highest death rates. The Board exempted them from all other duties, a major decision when it was short-staffed. ${ }^{65}$ They examined data up to and including 1917, thus excluding confounding mortality figures from the 1918-1919 influenza pandemic. They visited 26 asylums and compiled a short report in January 1919. They acknowledged non-war factors including asylum administration. They reiterated previously identified theories about overcrowding and poor nutrition, and commented that staff were unable to recognise early stages of illness, nurse the patients, or have sufficient time to maintain ward cleanliness. They attributed inequitable food distribution to inexperienced or temporary attendants, although that is hard to believe: serving food was hardly a scientific or specifically nursing skill. ${ }^{66}$ The Board acknowledged that War Office demands, such as transferring sick patients between asylums to create the war hospitals, could have contributed to the spread of infection. ${ }^{67}$ It also considered relevant the effects of the bitterly cold winter of 1916-1917, coupled with unsuitable buildings, fuel shortages and inadequate ward heating, all causes outside the Board's direct control. ${ }^{68}$ Overall, the Board's statements characteristically passed the buck, rather than arguing that it could have taken more responsibility for vulnerable people under its care. Some VCs ignored the Board's report. ${ }^{69}$ However, the Board affirmed its faith in the VCs who had to deal with the many challenges, and stated that "Asylum Authorities are alive to these difficulties, and that, as far as possible, they will endeavour to improve existing conditions."70 However, the long-term failure to implement changes to help control tuberculosis since Crookshank's paper, suggests that their hope was wishful thinking. Without the power to mandate changes or permit the asylums greater financial flexibility, the Board had little alternative but to trust the VCs.

Godias Drolet, a statistician, analysed patterns of death from tuberculosis during, before and after the war. He identified peaks of mortality in several European countries, including in Denmark, the Netherlands, Belgium, Ireland and the United Kingdom. ${ }^{71}$ Tuberculosis mortality peaked in 1917-1918 in many countries whether or not involved directly in the conflict, and allowing for different methods of data collection and a degree of error. ${ }^{72}$ After the war, community tuberculosis rates fell to a level which would have been predicted if the rise had not occurred. When the rate across England changed, so did that in the asylums. Why 
the death rate fell to below its pre-war level so rapidly is an unsolved mystery for which material changes do not fully account. ${ }^{73}$

Crammer argued that, in its zeal for the war effort, the Board "abandoned the patients whose care they were supposed to safeguard" and that it was responsible for the excess mortality. ${ }^{74}$ Crammer focussed on nutrition, overcrowding and understaffing, but did not discuss many other factors including the neglected high rates of asylum tuberculosis prewar; inadequate processes of, and responses to, disease notification; poor hygiene and ventilation; lack of heating and harsh winters; inexperienced and temporary staff; complacent leadership; tuberculosis epidemiology; and budgetary constraints. It is easy to blame the wartime authoritiesthe Board, VCs, MOHs, MPA and medical superintendents-who let much pass, but if blame is due, it also falls on those who for over a decade pre-war were complacent and failed to make any serious attempt to reduce asylum tuberculosis.

\section{Tuberculosis at Claybury and Hanwell: Case Studies}

Pre-war, Mott identified more tuberculosis at Claybury than in other LCC asylums, although figures were partly dependent on post-mortems for which interpretation varied between pathologists. ${ }^{75}$ Despite Mott's evidence, Claybury's medical superintendent, Robert Armstrong-Jones, asserted in 1914 that during his two-decade leadership the "tuberculosis death-rate was smaller than that of most of the other London asylums". ${ }^{76}$ Typically, the VC did not challenge their medical superintendent's analysis, which lessened the pressure on them to examine or improve asylum practices.

Mid-war, Claybury faced numerous senior staff changes. ArmstrongJones retired in 1916 and the VC appointed a succession of acting medical superintendents. First, they promoted the senior assistant medical officer, Charles Ewart, but he died soon after. The second, Thomas Fennessy, also already on the staff, left to serve in the forces ${ }^{77}$ and was killed when the steamer Leinster was torpedoed. ${ }^{78}$ In mid-1917, the VC appointed Guy Barham from Long Grove Asylum. He had a broad clinical experience, having worked as resident medical officer in a general hospital and as emergency officer at the London Hospital, Whitechapel. ${ }^{79}$ Other senior "acting" appointments included the head night attendant. ${ }^{80}$ Matron Margaret Russell retired after 36 years' service, ${ }^{81}$ and the steward 
left, suffering from mental problems. ${ }^{82}$ The LCC research laboratories with their staff, including Mott, were relocated to the Maudsley Hospital. ${ }^{83}$ The many changes of senior personnel may have destabilised asylum management, practices and monitoring, with adverse outcomes for patients.

Casting a new pair of eyes on Claybury, Barham noted some disturbing legacies from his predecessors suggesting low standards of care. Falls and "accidents" to patients were excessive, storage of dangerous drugs was unsafe, and observation of patients at risk of suicide was inadequate. In November 1917, he raised his concerns with the VC. A couple of months later, when an outbreak of dysentery caused 36 deaths, Barham took the unusual step, before seeking the VC's agreement, of asking the local authorities to suspend admissions temporarily. ${ }^{84}$

From late 1917, Claybury had almost 70 deaths each month (from all causes), compared to an average monthly death rate of 20 during the previous two decades. ${ }^{85}$ In April 1918, the VC discussed an outbreak of typhoid and Barham announced that he was seeking advice from a public health expert, William Hamer, the LCC's MOH. Seeking external medical advice was rare: it might give the impression to the VC that a medical superintendent did not know how to do his job, making him vulnerable to criticism or dismissal. Barham and Hamer joined forces to investigate the deaths. ${ }^{86}$ A lawyer, Lionel Shadwell, inspected Claybury in June 1918 on behalf of the Board, unaccompanied by a doctor. He noted the high death rate from "natural and ordinary" causes. He showed little concern about these deaths, noting that suicide and accident rates, which might require legal action, were acceptable. Overall, he described the asylum as "creditable". ${ }^{87}$ Shadwell's comments give credence to the suggestion that legal Board members overlooked medical matters.

Deaths declined during the summer, attributed to the warmer weather. In September 1918, Barham warned that the temperature inside the building needed to be kept around $55-60 \mathrm{~F}\left(13-15^{\circ} \mathrm{C}\right)$, otherwise "a very high death rate may be expected." 88 A month later the VC minutes recorded: "With the approach of the cold weather, and the need for greater economy in the use of fuel even than last year, when the heating of the building was kept low, a continued high death rate seems inevitable." 89 Despite Barham's concern, the VC appeared blasé. Later in the year, Barham announced the recommendations from his and Hamer's study, largely reiterating those from earlier research which had been ignored. At the same meeting, the VC said that it would consider 
requesting up to 300 more tons of coal above the rationed level. ${ }^{90}$ The war had just ended, but intense shortages persisted. No reasons for the VC's abrupt about-turn were stated, but Barham's and Hamer's report was likely to open the asylum to further scrutiny by the LCC.

Hanwell also appointed an acting medical superintendent in 1917: Alfred Daniel replaced Percy Baily who had been on the staff since 1890. ${ }^{91}$ Like Barham at Claybury, Daniel challenged established customs and practices, and cautiously and humanely advocated for the needs of patients in a way which was not evident in the later years under Baily's control. ${ }^{92}$ Increasing tuberculosis mortality at Hanwell (10 deaths in 1913, 49 in 1917) alarmed Daniel. He attributed this to insufficient ward ventilation ("the general stuffiness that prevailed today cannot be healthy"93), lack of time in the open air, and unhygienic habits: "they spit about the wards promiscuously, the sputum dries and is inhaled by the healthy." Painted windows to comply with lighting restrictions prohibited opening them in the evenings, and lack of heating and insufficient bed linen discouraged opening them at night. ${ }^{95}$ In April 1918 the VC and the asylum engineer agreed to Daniel's proposal to erect two "tuberculosis shelters" using scaffolding and tarpaulins, so at least some of the 58 known cases could sleep out of doors. ${ }^{96}$

For both recently appointed acting medical superintendents, Daniel at Hanwell and Barham at Claybury, their assertive proposals to improve conditions for patients did not fall on deaf ears. This raises questions about the asylums' leadership strategy. Lay VCs appeared overly respectful of the judgement and expertise of their own medical superintendents, who may, in their long-term jobs-for-life roles, have been "burnt-out", associated with apathy, at a time when confronted by additional wartime challenges.

\section{Other Infections: Dysentery, TYPHOID AND INFLUENZA}

During the war, dysentery and other forms of infective diarrhoea increased in many, but not all, public asylums. ${ }^{97}$ Advice about prevention and treatment included isolating patients, preferably in a separate building, disinfecting all items in contact with them, and prescribing small quantities of neat brandy orally and starch-and-opium enemas if diarrhoea was severe. ${ }^{98}$ It is unclear whether the advice was followed at Colney Hatch in 1917 when 130 people caught dysentery, half of whom died. ${ }^{99}$ 
The Board was keen to discover why, according to Mott's records since 1902, some asylums had no dysentery, while in others it was endemic and in others intermittent. ${ }^{100}$ In the community, dysentery was rare. ${ }^{101}$ It was also rare in private mental hospitals, ${ }^{102}$ pointing to the infection being a factor of the institution, rather than an intrinsic risk of mental disorder as proposed by degeneration theories of a single predisposition to both. Staff also caught it, including kitchen workers, with an alarming potential for transmitting it. ${ }^{103}$ Dr. Shaw Bolton, subsequently medical superintendent and professor at Wakefield Asylum, learnt the hard way about its transmissibility while an assistant medical officer at Claybury:

He had started his tea one afternoon in the medical officer's room, when he was sent for to go and see a patient who had suddenly collapsed, a woman. After seeing her he gave instructions for the usual treatment, and went back to finish his tea without first washing his hands. Five days later he had an unpleasant attack of dysentery. At Claybury, about 1900-1903, it was not the fashion to believe that sane persons could catch the disease! ${ }^{104}$

The bacterium shigella was the usual causal agent of dysentery. Signs and symptoms included fever, stomach cramps, ulceration of the large intestine, haemorrhage and bloody diarrhoea. ${ }^{105}$ In 1914, the Board funded research into its nature, prevention and treatment. ${ }^{106}$ The research took place at Wakefield Asylum, then under Shaw Bolton's leadership, where dysentery had been endemic since the asylum opened in 1818. ${ }^{107}$ The pathologist there, Harold Gettings, aimed to detect carrier status, preferably by a blood test since it was "impossible to get officers in large asylums" to test faeces, even where suitable laboratory facilities were available. ${ }^{108}$ Gettings modelled his goal on other tests for detecting early infections and carrier states ${ }^{109}$ : the tuberculin test for tuberculosis, Wassermann test for syphilis, and Widal test for typhoid. Unfortunately, Gettings did not know that asymptomatic carrier status for dysentery was rare. ${ }^{110} \mathrm{He}$ also aimed to produce a vaccine to prevent the disorder, although a century on, this has still not been achieved. ${ }^{111}$

In 1915, the Medical Research Committee (MRC, predecessor of the Medical Research Council) criticised the Board for sponsoring Gettings' dysentery research, a physical illness. It did not understand the diversity and complexity of physical and mental conditions coexisting in the asylums, or that the Board wanted research to benefit patients directly and promptly. Around the same time, the War Office wanted the MRC to 
provide solutions for the crisis of dysentery affecting troops in the Dardanelles, so the MRC took over funding Gettings' research. This allowed the Board to use its resources for other projects with a more specific mental health focus. The Board and the MRC also created a longer-term plan of collaboration "to establish a wider national scheme for research into mental diseases". 112

Typhoid (enteric fever), another infectious disorder, was also far more common in asylums than in the community. ${ }^{113}$ As with tuberculosis and dysentery, typhoid affected staff and patients. ${ }^{114}$ As with dysentery and tuberculosis, good hygiene and quarantining could help prevent transmission. ${ }^{115}$ Typhoid carriers could be identified by the Widal test and immunisation was available, unlike the options for dysentery. ${ }^{116}$ At risk patients, and staff such as laundry women dealing with foul linen, were offered and usually accepted immunisation, although occasionally one refused and succumbed to the infection. ${ }^{117}$ Occasionally and unexpectedly, patients who were predicted to become long-stay, improved mentally after an episode of typhoid, allowing them to be discharged. This outcome reinforced the belief in overlapping aetiologies of mental and physical illnesses, giving rise to speculation about the effects of infection, inflammation and immunisation and the possibility of prevention and treatment of mental disorders. ${ }^{118}$

"Spanish" influenza, another devastating infection, added to wartime adversities. Influenza prevailed among soldiers on both sides of the conflict in spring 1918. In mid-1918, mortality from the disorder increased world-wide. The unusual summer timing of the first outbreak worried public health officials who predicted a second wave. ${ }^{119}$ It came: the biggest and most fatal, in autumn 1918, and a third in spring 1919. ${ }^{120}$ The magnitude and unexpectedness of the pandemic overshadowed the end of the war. The war took the lives of 10 million people, and the pandemic killed over 40 million world-wide. About 700,000 British soldiers were killed in the war, and 225,000 people died from 'flu in Britain, 70,000 in November 1918 alone. ${ }^{121}$ The nation did its duty according to expectations inculcated into it during the war: it stoically "carried on". The Local Government Board in Whitehall, responsible for public health, did little apart from issuing an occasional memorandum. ${ }^{122}$

A combination of military and civilian hardships probably increased people's vulnerability to 'flu: insanitary trenches; overcrowded military ships and trains; women exhausted from war work plus their domestic chores; and a medical system largely geared to military needs. The 'flu 
was particularly lethal to young adults, but there was little association between mortality and social class or overcrowding in domestic dwellings. The Board was unable to explain the pattern of influenza incidence and mortality in the asylums. Eleven asylums had no deaths during the most devastating wave, including one asylum which otherwise had extremely high mortality rates. ${ }^{123}$ In some, either men or women died, but not both. ${ }^{124}$ At Claybury in November 1918, female staff were affected disproportionately more than male staff or patients and, along the lines of the example set by Barham at the time of the dysentery outbreak a few months earlier, the asylum took the precaution of suspending female admissions. ${ }^{125}$ Some potentially harmful practices continued, such as certifying and transferring severely physically ill patients from the community and general hospitals to the asylums. ${ }^{126}$ Some were so ill at the time of transfer that they died soon after. The Board advised against moving such patients, whose mental disturbances were probably due to delirium resulting from the 'flu. It used the opportunity to highlight the inadequacy of general hospital facilities, particularly for treating people with physical disorders whose associated mental impairment was likely to be temporary. ${ }^{127}$

\section{CONCLUSIONS}

Reflecting on the chronic high levels of asylum tuberculosis pre-war, and the tragedy of the devastation it caused during the war, psychiatrist Lionel Weatherly commented in 1919: "the death-rate of tuberculosis in our large asylums is a standing disgrace to our country, and I earnestly hope something will soon be done to mitigate this crying evil." 128 Managing infectious diseases in asylums was characterised by poor coordination, fragmented and poor communication and leadership indifference. There were scientific uncertainties, but much was known and was not applied. The system was peppered with inequalities, unjustifiable on medical or public health grounds, such as providing sanatorium treatment for asylum staff but not for patients. This gives the impression of clinical decision-making being related to an individual's or a group's perceived social and economic value: staff were seen as workers who could contribute whereas mentally unwell people were a drain on resources. The focus on employment was compatible with the National Insurance Act 1911 which provided health insurance for breadwinners but not for their dependants. 
Crammer asked why the Board failed to solve the problem of rising deaths. He answered that in its zeal for the war effort, the Board "did not try very hard" and it "abandoned" its patients. ${ }^{129}$ The Board passed the buck on some health-related issues. It acted sluggishly on others. The culture was to make do and continue, to self-justify and not to seek more, although at some point that conflicted with the medical ethical principle of primum non nocere, first do no harm. The Board had a duty to ensure humane care in its asylums, but it appeared to lack the skills and assertiveness to tackle some of the tasks demanded of it. Its decisions at the beginning of the war may have been suitable for a short-term conflictand many believed that was what it would be ${ }^{130}$ _but evidence is lacking to suggest significant revision of plans in the context of a prolonged war. In addition, if Board inspections were to be meaningful, they needed to be undertaken by people who had sufficient clinical experience and judgement, otherwise they would fit the requirements of administrators rather than the needs of patients and staff.

Some well-established medical superintendents, despite their expertise, appeared complacent or burnt-out after two decades of consistently taking enormous responsibility. With complacent medical leadership, it is hardly surprising that the lay VCs ignored potentially relevant scientific findings which were difficult to weigh up and interpret. In contrast to the longestablished medical superintendents at Claybury and Hanwell, their newly appointed replacements challenged the VCs and advocated more for their patients.

Excessive infections in asylums during the war were probably associated with a large pre-war reservoir of infective micro-organisms. This baseline helps explain their relative frequency and rise during the war compared to the same diseases in the general population. For tuberculosis, the authorities had failed to act on the advice of the MPA and others to attempt to reduce infection and mortality by any means known. Asylums knew what to do, but did too little, too late. Post-war, the Board made recommendations based on its report about asylum mortality, noting that war conditions alone did not account for the "alarming increase" in asylum sickness and that the asylums should improve their hygiene and public health measures. ${ }^{131}$ It advised the asylums what to do, much as it and its predecessor, the Commissioners in Lunacy, had done unsuccessfully for over a decade pre-war. Plus ça change, plus c'est la même chose. 


\section{Notes}

1. Colney Hatch $\mathrm{H} 12 / \mathrm{CH} / \mathrm{B} / 16 / 003$ Case notes of female patients who died in 1918-1919 LMA.

2. Colney Hatch $\mathrm{H} 12 / \mathrm{CH} / \mathrm{B} / 22 / 014$ Autopsy book for female patients 1916-1918 LMA; Charles Mercier, The Attendant's Companion: A Manual of the Duties of Attendants in Lunatic Asylums (London: J and A Churchill, 1898), 76; First Annual Report of the Board of Control, for the Year 1914 (BoC AR 1914) (London: HMSO, 1916), Part 2, Hereford County and City Asylum 4 May 1914, 235.

3. William Stoddart, Mind and Its Disorders (London: Lewis, 1908), 424.

4. Stoddart, Mind, 421; Robert Branthwaite, Some Observations on the Prevalence of Tuberculosis, Dysentery, and "Severe Diarrhoea" in Mental Hospitals (London: HMSO, 1923); Patrick O'Doherty, "Some Features of the Recent Outbreak of Enteric Fever at Omagh District Asylum," Journal of Mental Science (JMS) 60 (1914): 76-81, 80.

5. Colney Hatch $\mathrm{H} 12 / \mathrm{CH} / \mathrm{B} / 47 / 016$ Letter to VC from Elsie's friend (name illegible), 30 April 1918 LMA.

6. Colney Hatch $\mathrm{H} 12 / \mathrm{CH} / \mathrm{B} / 47 / 016$ Reception orders, medical certificates, notices of death, discharge or removal and correspondence for female patients who died or were discharged or removed 1918, LMA.

7. BoC AR 1914, Part 2, Causes of deaths in all lunacy institutions, 87-98.

8. LCC LCC/MIN/00583 Meeting, 27 November 1917, 169 LMA.

9. Sixth Annual Report of the Board of Control, for the Year 1919 (London: HMSO, 1920) (BoC AR 1919), Appendix A: 20.

10. John Crammer, "Extraordinary Deaths of Asylum Inpatients During the 1914-1918 War," Medical History 36 (1992): 430-441, 431.

11. Ayers Gwendoline, England's First State Hospitals and the Metropolitan Asylums Board, 1867-1930 (London: Wellcome Institute of the History of Medicine, 1971), 230.

12. Waltraud Ernst, "The Limits of Comparison: Institutional Mortality Rates, Long-Term Confinement and Causes of Death During the Early Twentieth Century," History of Psychiatry 23 (2012): 404-18, 405.

13. Fifth Annual Report of the Board of Control, for the Year 1918 (London: HMSO, 1919) (BoC AR 1918), Appendix B: 31-32.

14. BoC AR 1914, Part 2, Bucks Asylum 30 October 1914, 201.

15. Anon. The LCC Hospitals: A Retrospect (London: LCC, 1949), 105; Ernst, "The Limits of Comparison": 405.

16. Frederick Mott, "Tuberculosis in London County Asylums," Archives of Neurology and Psychiatry from the Pathological Laboratory of the London County Asylums, Claybury, Essex 4 (1909): 70-116, 84, 115; Jennifer Wallis, Investigating the Body in the Victorian Asylum (London: Palgrave Macmillan, 2017), 226; Fourth Annual Report of the Board of Control, for the Year 1917 (London: HMSO, 1918) (BoC AR 1917), 15. 
17. James Ritchie, "Hypertrophy and Atrophy," 217-23, in Text-Book of General Pathology, ed. MS Pembrey and James Ritchie (London: Edward Arnold, 1913), 219-20.

18. Hanwell H1l/HLL/B/31/006 Post-mortem register, males, 19151917 LMA.

19. Colney Hatch $\mathrm{H} 12 / \mathrm{CH} / \mathrm{B} / 23 / 013$ Autopsy book for male patients 1916-1918 LMA.

20. Hanwell Hll/HLL/B/31/006 Post-mortem register, males, 19151917 LMA.

21. BoC W/FM, 4 February 1920, 35 MH 50/48 TNA.

22. Claybury LCC/MIN/00948 Meeting, 26 April 1917, 88 LMA.

23. Hanwell LCC/MIN/01093 Meeting, 8 December 1913, 5-6 LMA.

24. Pamela Michael and David Hirst, "Recording the Many Faces of Death at the Denbigh Asylum, 1848-1938," History of Psychiatry 23 (2012): $40-51,50$.

25. Mott, "Tuberculosis in London County Asylums": 85.

26. Francis Crookshank, "The Frequency, Causation, Prevention, and Treatment of Phthisis Pulmonalis in Asylums for the Insane; Essay for Which Was Awarded the Bronze Medal of the Medico-Psychological Association, 1899," JMS 45 (1899): 657-83, 667.

27. Crookshank, "Frequency": 668.

28. Crookshank, "Frequency": 670.

29. Crookshank, "Frequency": 673-74.

30. William Menzies, "Some Points Connected with Tuberculosis in Asylums," JMS 51 (1905): 548-60.

31. Stoddart, Mind, 422.

32. Mott, "Tuberculosis in London County Asylums": 113, 116.

33. BoC AR 1914, Part 2, Upton Asylum 16 March 1914, 207.

34. Mott, "Tuberculosis in London County Asylums": 113, 116.

35. BoC AR 1914, Part 2, Salop Asylum 8 July 1914, 298; Plymouth Borough Asylum 22 May 1914, 374; BoC, "Food Allowances," 23 July 1918, 513 MH 51/239; John Murray, "Tuberculosis and World War I," American Journal of Respiratory and Critical Care Medicine 192 (2015): 411-14, 413.

36. Murray, "Tuberculosis and World War": 411; BoC, letter to MSs, January 1915, MH 51/239 TNA.

37. Murray, "Tuberculosis and World War": 414; HL Rieder, Epidemiologic Basis of Tuberculosis Control (Paris: International Union Against Tuberculosis and Lung Disease, 1999).

38. BoC AR 1914, Part 2, North Wales Asylum 20 March 1914, 215; BoC, "Increased Annual Death Rate in Asylums," 15 January 1919 MH 51/239 TNA; Hanwell LCC/MIN/01098, 8 April 1918, 6-7 LMA; BoC AR 1918, 25. 
39. BoC AR 1914, Part 2, Bexley Asylum 20 March 1914, 266; Northumberland Asylum 4 May 1914, 292.

40. Third Annual Report of the Board of Control, for the Year 1916 (London: HMSO, 1917) (BoC AR 1916), 25-28.

41. Mercier, Attendant's Companion, 77-89. Anon. "Examination for Nursing Certificate," JMS 62 (1916): 644-45; BoC AR 1914, Part 2, Three Counties Asylum 16 June 1914, 195; Hants Asylum 6 November $1914,233$.

42. LCC LCC/MIN/00580 Meeting, 10 November 1914, 3 LMA.

43. Reginald Dudfield, "Reforms Needed in the Notification of TB," Proceedings of the Royal Society of Medicine (Proc RSM) 15 (1922): Section of Epidemiology and State Medicine, 75-92, 75.

44. Dudfield, "Reforms Needed": 78; Frank Spreat, Report of the Medical Officer of Health for the Year 1914 (Friern Barnet Urban District Council, 1915), 3, 19.

45. Branthwaite, Observations, 3.

46. Public Health England, Annual Tuberculosis (TB) Data for England and Wales, from 1913 Onwards (2013), https://www.gov.uk/government/ publications/tuberculosis-tb-annual-notifications-1913-onwards.

47. Branthwaite, Observations, 7-9.

48. Crammer, "Extraordinary": 430-31, 439.

49. BoC AR $1917,23$.

50. LCC LCC/MIN/00583 Meeting, 24 July 1917, 17 LMA.

51. BoC W/FM, 18 September 1918, 240-41 MH 50/46 TNA.

52. BoC, "Increased Annual Death Rate in Asylums," 15 January 1919, 532 MH 51/239 TNA.

53. Crammer, "Extraordinary": 437.

54. Godias Drolet, "World War I and Tuberculosis: A Statistical Summary and Review," American Journal of Public Health and the Nation's Health 35 (1945): 689-97, 692.

55. Murray, "Tuberculosis and World War": 413; Drolet, "World War I and Tuberculosis": 690.

56. BoC W/FM, 14 May 1919, 117 MH 50/47 TNA.

57. Peter Higginbotham, The Workhouse: The Story of an Institution, "The Workhouse in Wartime," http://www.workhouses.org.uk/wartime/.

58. Mott, "Tuberculosis in London County Asylums": 78.

59. Mott, "Tuberculosis in London County Asylums": 115.

60. Mott, "Tuberculosis in London County Asylums": 73.

61. Claybury LCC/MIN/00948 Meetings, 13 September 1917, 195-96; 3 January 1918, 286 LMA.

62. LCC LCC/MIN/00583 Meeting, 24 July 1917, 16 LMA.

63. LCC LCC/MIN/00583 Meeting, 24 July 1917, 5-7 LMA.

64. BoC W/FM, 18 September 1918, 240-41 MH 50/46 TNA. 
65. BoC W/FM, 9 October 1918, $262 \mathrm{MH} \mathrm{50/46} \mathrm{TNA.}$

66. BoC, "Increased Annual Death Rate in Asylums," 15 January 1919, $532 \mathrm{MH} \mathrm{51/239}$ TNA; BoC AR 1917, 23; Colney Hatch LCC/MIN/01003 Meeting, 18 December 1914, 215-16 LMA.

67. BoC AR 1914, Part 1, 15-16.

68. BoC AR 1917, 23.

69. Crammer, "Extraordinary": 437-38.

70. BoC AR 1919, 35.

71. Drolet, "World War I and Tuberculosis": 692.

72. Drolet, "World War I and Tuberculosis": 689.

73. Murray, "Tuberculosis and World War": 414.

74. Crammer, "Extraordinary": 441.

75. Mott, "Tuberculosis in London County Asylums": 74, 115.

76. Robert Armstrong-Jones in discussion on Harold Gettings, "Dysentery Past and Present," JMS 60 (1914): 39-56, 51.

77. Claybury LCC/MIN/00948 Meeting, 5 July 1917, 134-35 LMA.

78. Claybury LCC/MIN/00949 Meeting, 7 November 1918, 215 LMA; Sinking of Leinster, 10 October 1918, http://rmsleinster.com/.

79. The Medical Directory 1917 (London: J and A Churchill, 1917).

80. Claybury LCC/MIN/00948 Meetings: 19 July 1917, 167-68; 22 November 1917, 254 LMA.

81. Claybury LCC/MIN/00949 Meeting, 26 March 1918 LMA.

82. Claybury LCC/MIN/00948 Meeting, 19 July 1917, 169 LMA.

83. LCC LCC/MIN/00582 Meeting, 25 July 1916, 26 LMA.

84. Claybury LCC/MIN/00948 Meetings: 8 November 1917, 242-45; 3 January 1918, 290-91 LMA; Claybury LCC/MIN/00949 Meeting, 28 February 1918, 9 LMA.

85. Claybury LCC/MIN/00949 Meeting, 12 September 1918, 169 LMA.

86. Claybury LCC/MIN/00949 Meetings: 25 April 1918, 44-45; 20 June 1918, 86-88 LMA.

87. Claybury LCC/MIN/00949 Meeting, 20 June 1918, 86-88 LMA.

88. Claybury LCC/MIN/00949 Meeting, 12 September 1918, 169 LMA.

89. LCC LCC/MIN/00584 Meeting, 29 October 1918, 25 LMA.

90. Claybury LCC/MIN/00949, 5 December 1918, 233, 238, 239 LMA.

91. The Medical Directory 1890 (London: J and A Churchill, 1890).

92. Hanwell LCC/MIN/01097 Meeting, 17 December 1917, 253-54; LCC/MIN/01098 Meeting, 16 December 1918, 202-4 LMA.

93. BoC AR 1914, Part 2, Durham Asylum 8 May 1914, 222.

94. Hanwell LCC/MIN/01098 Meeting, 8 April 1918, 6-7 LMA.

95. Hanwell LCC/MIN/01096 Meeting, 9 October 1916, 200 LMA; Committee on the Administration of Public Mental Hospitals (Chairman: Sir Cyril Cobb) (Cobb Inquiry), 15 March 1922 Mr. Sale Q:664, 731, MH 58/219 TNA. 
96. Hanwell LCC/MIN/01098 Meeting, 8 April 1918, 6-7 LMA.

97. BoC AR 1916, 22, 25.

98. Stoddart, Mind, 426.

99. Colney Hatch LCC/MIN/01007 Meeting, 12 July 1918, 111-12 LMA.

100. Sidney Coupland in adjourned discussion on Gettings, "Dysentery," (1914): 43; BoC AR 1914, Part 1, 31; Branthwaite, Observations, 15.

101. Harold Gettings, "Dysentery, Past and Present," JMS 59 (1913): 60521,605 .

102. Branthwaite, Observations, 18.

103. Colney Hatch LCC/MIN/01007, 1 November 1918, 175 LMA.

104. J Shaw Bolton in adjourned discussion on Gettings, "Dysentery," (1914): 53.

105. Stoddart, Mind, 426-27.

106. Sidney Coupland, BoC, "Report on Replies to Circular Letter re: Scientific Research," 1914 MH 51/81 TNA.

107. J Shaw Bolton application for funding for study by Dr. Gettings, December 1914, MH 51/83 TNA.

108. J Shaw Bolton in adjourned discussion on Gettings, "Dysentery," (1914): 55.

109. J Shaw Bolton application for funding for study by Dr. Gettings, December 1914, MH 51/83 TNA.

110. Myron Levine, Herbert DuPont, Mohammed Khodabandelou, and Richard Hornick, "Long-Term Shigella-Carrier State," New England Journal of Medicine 288 (1973): 1169-71.

111. W Morley Fletcher and BoC, Meetings, 27 July, 21 September 1915 MH 51/86 TNA.

112. W Morley Fletcher and BoC, Meetings, 27 July, 21 September $1915 \mathrm{MH}$ 51/86, and correspondence, 26 February, 4 March $1915 \mathrm{MH} \mathrm{51/85}$ TNA.

113. BoC AR 1917, 39.

114. Colney Hatch LCC/MIN/01006 Meeting, 15 June 1917, 192 LMA.

115. BoC AR 1919, 30.

116. Claybury LCC/MIN/00948 Meeting, 21 June 1917, 125-26 LMA.

117. Colney Hatch LCC/MIN/01007 Meeting, 22 February 1918, 36 LMA; LCC LCC/MIN/00583 Meeting, 30 July 1918, 684 LMA.

118. O’Doherty, “Enteric Fever”: 80.

119. Arthur Newsholme, "Discussion on Influenza," Proc RSM 12 (1919): General Reports, 1-18, 12.

120. NPAS Johnson, "The Overshadowed Killer: Influenza in Britain in 1918-19," 132-155, in The Spanish Influenza Epidemic of 1918-19, ed. Howard Phillips and David Killingray (London: Routledge, 2003), 132. 
121. Johnson, “Overshadowed Killer": 132, 134.

122. Johnson, "Overshadowed Killer": 142, 150-51.

123. BoC AR 1918, 18.

124. BoC AR 1919, 31-32.

125. Claybury LCC/MIN/00949 Meeting, 5 December 1918, 241 LMA.

126. Claybury LCC/MIN/00948 Meeting, 3 January 1918, 286 LMA.

127. LCC LCC/MIN/00584 Meeting, 28 January 1919, 211-12 LMA; Tom Williams, "The Management of Confusional States with Special Reference to Pathogenesis," JMS 63 (1917): 389-400.

128. Lionel Weatherly, "The Incidence of Tuberculosis Amongst Asylum Patients," Lancet 6 September 1919, 456-57.

129. Crammer, "Extraordinary": 437, 441.

130. Imperial War Museum, "Voices of the First World War: Over by Christmas," (2018), https://www.iwm.org.uk/history/voices-of-thefirst-world-war-over-by-christmas.

131. BoC, "Increased Annual Death Rate in Asylums," 15 January 1919, 532 MH 5l/239 TNA.

Open Access This chapter is licensed under the terms of the Creative Commons Attribution 4.0 International License (http://creativecommons.org/licenses/ by $/ 4.0 /)$, which permits use, sharing, adaptation, distribution and reproduction in any medium or format, as long as you give appropriate credit to the original author(s) and the source, provide a link to the Creative Commons license and indicate if changes were made.

The images or other third party material in this chapter are included in the chapter's Creative Commons license, unless indicated otherwise in a credit line to the material. If material is not included in the chapter's Creative Commons license and your intended use is not permitted by statutory regulation or exceeds the permitted use, you will need to obtain permission directly from the copyright holder.

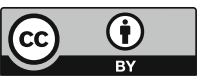

